\title{
On Keeping Medusae Alive in an Aquarium.
}

\author{
By
}

Edward T. Browne,

University College, London.

I HAVE made several attempts to keep medusae alive in an aquarium, but have only recently been successful. A medusa when first placed in an aquarium swims actively about, but in a few hours it sinks to the bottom apparently tired out. After an interval of rest it takes another swim and again sinks to the bottom. This is repeated until the medusa becomes completely exhausted; then it stays at the bottom and slowly dies. In spite of every attention, plenty of clean sea-water, plenty of copepods, and a suitable temperature, I found that my medusae often used to die within a day of their capture.

When I have been watching medusae at the surface of the sea, I have noticed that they simply float along with the tide without often pulsating the umbrella. In my bell-jars the water was perfectly motionless, so that a medusa had to pulsate its umbrella in order to keep afloat, and as soon as the pulsations stopped it began to sink. There are some species, like those belonging to the Bougainvillidae, which live longer in confinement, as they are able to poise themselves in the water by the extension of their tentacles and remain motionless for long periods, but even these finally reach the bottom of the bell-jar, and a long period at the bottom ends in death.

It appeared to me that to keep medusae alive in an aquarium it was necessary to have the water in motion so that a medusa could float about just as it does in the sea, without having constantly to pulsate its umbrella. The intervals of floating are periods of rest.

I pass over the early experiments and describe a simple method for keeping water in motion in a bell-jar, which has given excellent results and has enabled me to keep medusae alive for many weeks in perfect condition. The current in the water is obtained by simply moving up and down, fairly slowly, a glass plate inside a bell-jar. Owing to the 
downward plunge the plate made in the early experiments it was called a "plunger," and this name I have retained for the want of a simpler one. (Fig. 1.)

The plunger consists of a flat glass plate with a small hole in the centre; through the hole passes a glass rod which is suspended to one end of a long wooden rod, the "beam." The glass rod has a knob at the bottom upon which the plate rests, and it is slightly bent so as to give a slope to the plate. The sloping of the plate prevents the medusae

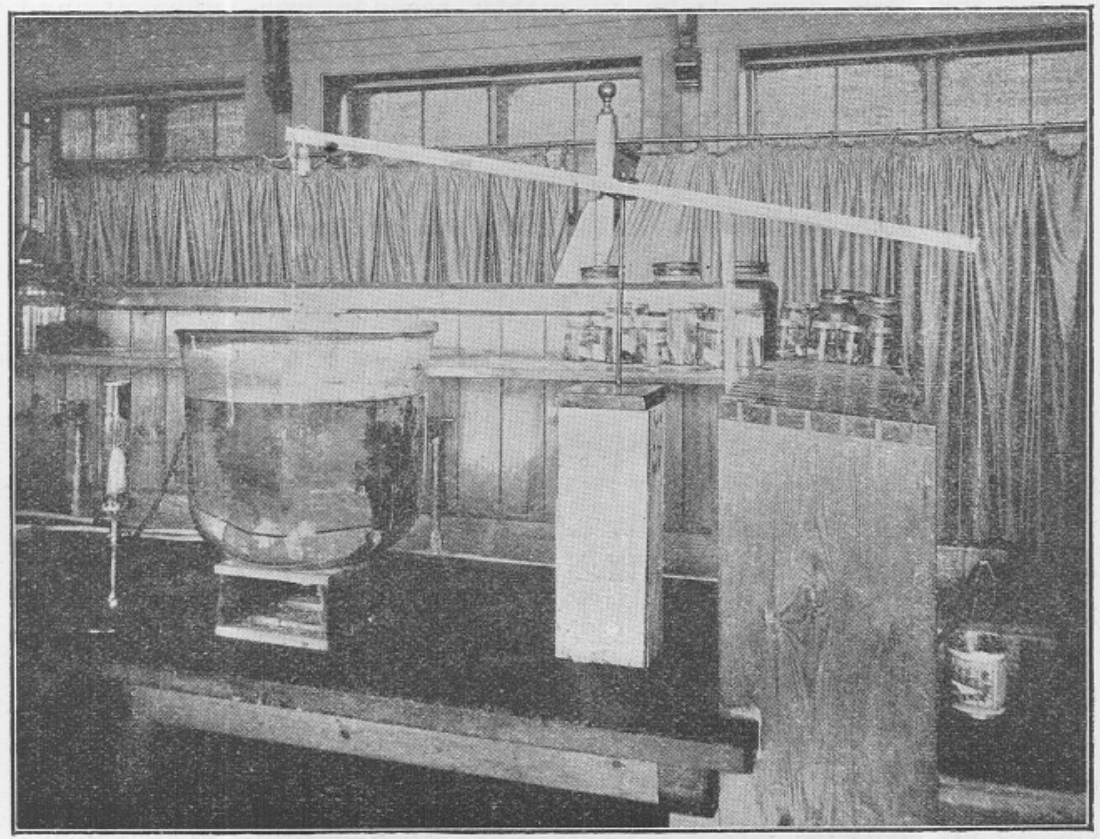

Fig. 1. Bell-jar with Glass Plunger.

being caught between the plate and the surface-film when the plunger moves up.

The beam rests near its centre on a pivot, like the beam of a balance. and at one end is suspended the plunger, and at the other end a small bucket made of tin, fitted with a large siphon. A rubber-tube conveys a constant flow of water (from the fresh-water supply) into the bucket which, when full, quickly empties itself through the siphon. When the bucket has been emptied by the siphon, the plunger is at the bottom of the bell-jar, as the plunger end of the beam is heavier than the bucket end. The plunger need only be a little heavier than the bucket; and the weight can be easily regulated by means of a bottle containing shot, attached to the beam. 
The siphon to empty the bucket must be of large bore, so as to carry away the water faster than it comes in. As soon as the siphon has stopped running the bucket begins to fill, and when the weight of the bucket exceeds that of the plunger, the bucket slowly goes down, and the plunger comes up to the surface. The length of the stroke is regulated by two stops, which prevent the beam moving too far up or down. The plunger remains at the surface until the water has reached the top of the siphon, and directly the siphon begins to act the bucket is quickly emptied, and the plunger goes down nearly to the bottom. I found that one down-stroke in eighty seconds was sufficient, and regulated the apparatus so that the down-stroke was a little faster than the up-stroke.

The top of the bell-jar has a wooden cover with a narrow slit cut in the centre to act as a guide to the plunger-rod, and to prevent the plate knocking against the bell-jar on the downward plunge.

The movement of the plunger produces numerous eddies in the water, which are rendered visible by the movements of the copepods and the medusae. The medusae are carried from one side of the belljar to the other, or from the bottom to the top. This movement the medusae appear thoroughly to enjoy, and during the intervals in which the plunger is at rest they may be seen either taking a swim or floating with their tentacles expanded, or else playing an active copepod, caught on the end of a tentacle, as skilfully as an expert angler plays a large fish.

The first plunger bell-jar was started in the Plymouth Laboratory on 4th of September. (Fig. 1.) The bell-jar contained about ten gallons of water, which had been in it about three months, and the glass was well coated with algae. In this bell-jar were placed at intervals different species of medusae, and a good food-supply consisting of copepods, crustacean larvae, \&c. I kept this bell-jar under close observation until the 9th of October, when my visit to Plymouth terminated. The temperature of the water was often taken, especially on hot days, and occasionally the specific gravity. The temperature varied from $1475^{\circ} \mathrm{C}$. to $17.5^{\circ} \mathrm{C}$., and it was kept down on hot days by placing round the outside of the bell-jar a strip of flannel, upon which played a jet of fresh water. This acted very well, for when the temperature of the room was about $21^{\circ} \mathrm{C}$., the water in the bell-jar remained about $16^{\circ} \mathrm{C}$.

All the species of medusae placed in this bell-jar not only lived longer, but were in a better condition than if kept in still water. Some species lived longer than others, which tends to show that much has yet to be learnt on keeping medusae. Perhaps for some species a slow revolving current would be better; it could easily be obtained by turning a screw-propeller in the water. 
The following notes on the inhabitants of the bell-jar may be of interest: About eighty specimens of Obelia lived very well for about ten days, and then began to die off. For the first week they kept in splendid condition, and were very active, but were not seen catching copepods. Obelia in an aquarium with still water usually lives about twenty-four hours.

Phialidium generally lives about three days in still water, but in the "plunger" bell-jar one specimen ( $P$. buskianum) lived six weeks, increased in size, and developed more tentacles. Its umbrella was as transparent as the clearest glass, and its tentacles were often seen stretched out, when fishing for copepods, to the fineness of a spider's web.

Another old inhabitant of the bell-jar was Phialidium cymbaloideum. In twenty-five days it added five new tentacles and five marginal bulbs.

The medusa of Lar sabellarum (Willsia stellata, Forbes) died suddenly after five weeks' captivity. It also added new tentacles, and increased the size of its umbrella. A specimen of Margelis lived seventeen days, and during this period added two new tentacles in each of the four marginal groups, and the oral tentacles twice dichotomously divided.

A single specimen of Sarsia gemmifera was placed in on the 16th of September. It started with six medusa-buds upon the manubrium; three of these developed into medusae which were liberated, and the others had nearly completed their development by the 9th of October.

These experiments I think show that it is possible to keep medusae alive in confinement for several weeks without any change of water, and that they increase in size and develop more tentacles.

In this bell-jar I placed copepods and crustacean and worm larvae as a food supply for the medusae. Whatever I placed in the bell-jar I examined with a microscope, to see that the specimens were in good condition. This applies not only to the medusae (it is useless. to place them in if at all damaged or about half dead), but also to the copepods, \&c.

Fresh copepods were added when the stock became low; some died a natural death, and many others were captured by the medusae. I did not try to keep alive the various pelagic larvae that were placed in the bell-jar, but I noticed that they throve wonderfully well. The larval form of Magelona was alive when I left Plymouth. It had been several weeks in the bell-jar, and was often seen floating with its two long tentacles stretched out to a considerable length. One worm safely passed through its larval stages, and built a tube on the bottom of the bell-jar. Mr. Garstang identified the adult form as Capitella capitata. Several of the crustacean larvae passed through their larval stages. I saw an adult form of a shrimp, and Mr. Hodgson identified another crustacean for me as the adult of Nika edulis. 
In another plunger bell-jar I placed a colony of Syncoryne. It soon sent out long stolons attached to the glass. I measured and made drawings, at intervals, of the new growth of the colony. In thirteen days the total length of the new stolons and branches amounted to $773 \mathrm{~mm}$., and ninety-nine new hydranths appeared. In this bell-jar I also kept some medusae liberated from hydroid colonies of Perigonimus. When the medusa leaves the colony it has two long perradial tentacles. In twelve days one specimen possessed four long perradial tentacles, four interradial bulbs, and one adradial bulb. The other specimens were not quite so far advanced.

I tried the experiment of starting with a perfectly clean bell-jar and using filtered sea-water, in which a plunger worked. Into this belljar, holding about two gallons, I placed about three dozen medusae and a good supply of copepods. The medusae were not specially selected, but taken as a sample of a day's tow-netting. I did not interfere with them for ten days, but only added copepods when the supply became low, when I found thirty-one specimens alive, and more than half of them were in excellent condition.

I must express my sincere thanks to my friend Mr. E. J. Allen for the great amount of trouble and the many useful suggestions which he made when we fitted up the apparatus for working the first plunger bell-jar. It was his suggestions which led to the plunger being worked by such a simple method. 